\title{
Pass-Through Rates for Alcohol Beverage Excise Taxes: Fixed-Effect versus Random-Effects Meta-Analysis and Meta-Regressions
}

\author{
Jon P. Nelson \\ Department of Economics, Pennsylvania State University, University Park, PA, USA
}

Received May 18, 2021; Revised August 11, 2021; Accepted August 24, 2021

\section{Cite This Paper in the following Citation Styles}

(a): [1] Jon P. Nelson, "Pass-Through Rates for Alcohol Beverage Excise Taxes: Fixed-Effect versus Random-Effects Meta-Analysis and Meta-Regressions," Advances in Economics and Business, Vol. 9, No. 2, pp. 23 - 41, 2021. DOI: 10.13189/aeb.2021.090201.

(b): Jon P. Nelson (2021). Pass-Through Rates for Alcohol Beverage Excise Taxes: Fixed-Effect versus Random-Effects Meta-Analysis and Meta-Regressions. Advances in Economics and Business, 9(2), 23 - 41. DOI: 10.13189/aeb.2021.090201.

Copyright $\odot 2021$ by authors, all rights reserved. Authors agree that this article remains permanently open access under the terms of the Creative Commons Attribution License 4.0 International License

\begin{abstract}
This paper extends an earlier study to compare two methods for meta-analysis of economic data: fixed-effect models and random-effects models. The models differ fundamentally in the ability to generalize beyond the sample in question. Both models are applied to estimates of pass-through rates for excise taxes on alcohol beverages. Using best-set data from 30 primary studies, weighted means are first reported and compared against a fully-passed tax or rate of unity. Dispersion and heterogeneity statistics are used to assess the performance of each model. Second, means and dispersion statistics are reported by subgroups for country source, beverage (beer, wine-spirits), and published status. Third, tests are conducted for publication selection bias using funnel plots and regression asymmetry tests. Fourth, three procedures are undertaken to reduce selection bias: trim-and-fill; cumulative meta-analysis; and meta-regressions. Three conclusions are reached in the paper. First, average pass-through rates are approximately unity regardless of beverage. Primary researchers should compare estimated rates against this value. Second, a random-effects model is more appropriate for these data, reflecting highly diverse estimates of pass-through rates. Third, greater attention needs to be given to the choice of model for meta-regressions in economics and related disciplines.
\end{abstract}

Keywords Excise Taxes, Tax Pass-Through, Meta-Analysis, Publication Bias

\section{Introduction}

During the past thirty years, numerous meta-analyses have been published in economics and related areas. ${ }^{1}$ Typically these analyses obtain a sample of empirical studies from the literature on a particular subject and then summarize or synthesize the distribution of estimates using precision weighted-means and meta-regressions. Covariates or moderators in regressions include variables that describe primary data samples (e.g., country source, panel data) and methods employed by primary investigators (e.g., OLS). Categorical variables are frequently used as moderators, thereby creating subgroups for analysis. Despite the high degree of heterogeneity that exists in economic data and studies, an overwhelming majority of meta-analyses in economics employ a conditional or fixed-effect size (FES) model to summarize and analyze study results. However, FES models assume that sampled estimates represent the only population of interest, which means analytical results should not be generalized beyond these data [1]. In the limiting case of a

1 A search of EconLit using the search term "meta-analysis" in the field for "Abstract" returned 1,186 citations for 1986-April 2021, with about half of the citations appearing since January 2013. 
common-effect model, there is only one true population effect. Possible sources of variation in a FES model are sampling error; observed differences in data and methods used by primary investigators; and publication bias. This characterization of a FES model is explained in detail by Hedges and Vevea [2]; see also [3,4]. In contrast, a model of random-effects size (RES) assumes a priori the primary estimates are a sample from a larger population of potential studies [5]. The RES or plural-effects model is appropriate if primary study estimates are representative of a universe of comparable populations and the objective of the meta-analysis is to generalize in terms of a grand mean and variation around that mean. The universe in question might be suggested by the analyst, but it is likely that readers and policymakers also are prone to generalize. In a RES model, variation of true effects across populations - the estimated between-study variance - is explicitly incorporated in the analysis, thereby controlling for an additional source of dispersion. In contrast, a FES model assumes the between-study variance is zero or nearly so, which implies perfect homogeneity of true effects. Hence, inferences beyond the sample of estimates should not be carried out using a FES model. The population is clearer in a FES model which limits inferences, but a RES model permits unconditional inferences to broader populations [2]. Choice of model and attendant weights is therefore an important aspect of any meta-analysis. ${ }^{2}$

The objective of this paper is to illustrate how results from a RES model can differ from those in a FES model, reflecting unobserved or random heterogeneity in a sample of estimates. The paper extends a prior narrative review [6] to focus on the choice of model for a meta-analysis by using empirical estimates for pass-through rates for excise taxes levied on alcohol beverages, i.e., effect size estimates measure the extent to which a one cent increase in a tax causes change in retail prices of alcohol. A pass-through of unity is a fully-shifted tax and provides a convenient benchmark for the null hypothesis. Both FES and RES models allow that mean pass-throughs can be greater or less than unity, so a chief difference is the range of possible inferences. As demonstrated below, there is substantial dispersion of estimates, which suggests use of a RES model. Data on pass-throughs rates are contained in 30 primary studies (Appendix A), which cover alcohol excise taxes and prices for beer, wine, or spirits. There are 16 studies for the U.S. and 14 studies that use data for European nations, groups of countries (EU, OECD), and various other nations (Japan, South Africa). Primary studies use data that cover alcohol taxes and prices for individual brands, cities, states, or the nation. As is typical in economics, the

2 The terms "fixed-effect" and "random-effects" refers to different weightings used in each case and should not be confused with similar terminology used in panel data econometrics. diversity of econometric methods employed by primary researchers is substantial and range from simple OLS estimates based on aggregate time series [7] to scanner prices and panel data at the city level [8]. No two studies are identical. A variety of special issues also are addressed in primary studies such as border effects arising from tax increases in one jurisdiction [9] or pass-through rates that vary across the price spectrum [10]. These issues are not addressed here, but methods and results are described at length in the prior review [6]. ${ }^{3}$ Primary estimates for special issues are ignored here as the focus is on price impacts at the beverage level or for all alcohol beverages combined.

The choice of FES vs. RES models is crucial as the starting point for a meta-analysis. However, relatively few analyses in economics dwell on this distinction or inform readers that a FES analysis cannot be extended or generalized beyond the collection of primary studies, e.g. $[11,12]$. Nelson and Kennedy [13] surveyed 140 meta-analyses in environmental economics, where an out-of-sample benefit transfer was often an objective. Only 22 studies employ a RES model for meta-regressions. Reflecting the diversity of methods and estimates present in the pass-through literature, the present paper addresses similarities and differences between the models and presents results for both weighted-means and meta-regressions for alcohol tax pass-through rates. The study presents a more general method for meta-analysis of economic data, which should be an aid to decision-making on a variety of issues.

The remainder of the paper is organized as follows. First, following a description of the data, weighted-means are reported for fixed and random-effects for all alcohol beverages, together with various statistical indexes that describe dispersion and heterogeneity in these data. Indexes reported include the prediction interval for random-effects, which is a recent addition to methods used in meta-analysis $[4,14,15]$. Second, data are divided into subgroups with the analysis repeated for: (1) U.S. vs. not-U.S. estimates; (2) beer vs. wine-spirits estimates; and (3) published studies vs. not-published studies. Methods of analysis for subgroups include the mixed-effects model, which assumes subgroups are fixed but estimates within each group are random. Third, results are reported for funnel plots, Egger's test for plot asymmetry, and a cumulative meta-analysis that quantifies the influence of less-precise estimates. Fourth, results are reported for meta-regressions with moderators for data and method, with attention given to issues of publication selection bias. Moderators in meta-regressions test for dispersion due to observable heterogeneity. Fifth, results are summarized with a focus on current practice in economics. Overall,

3 Nelson and Moran [6] also provide a preliminary meta-analysis of two data samples, with a focus on weighted-means. The present study focuses on the critical issue of choice of model, either fixed- or random-effects (or both). 
both FES and RES models support a pass-through of unity across beverages, but dispersion around that value is substantial. Hence, a RES model is more appropriate for these data, particularly for purposes of value transfers and similar policy applications. Future primary studies of tax rates should compare estimated values to a rate of unity in addition to the usual tests for statistical significance.

\section{Methodology: Fixed- vs. Random-Effects Weighted-Means}

\subsection{Methods and Materials}

Effect-size estimates are pass-through rates for excise taxes on alcohol beverages. Pass-through rates are important as a component of optimal alcohol tax calculations for various countries [16]; price elasticity calculations [17: 72]; and as indicators of the incidence of such taxes. ${ }^{4}$ A rate or effect size of unity is consistent with a competitive market, operating with a perfectly elastic supply schedule. Positive pass-through rates of less than unity also may occur due to supply-side inelasticity. Rates greater than unity are generally believed to be due to imperfectly competitive markets $[18,19]$, but other causes are possible (e.g., menu costs of price changes, vertical market structures). Hence, the null hypothesis in the present study is an average rate that is not statistically different from unity, but alternative values can be greater or less than unity. A focus in the empirical work is the range of values indicated by confidence intervals and prediction intervals, and not just point estimates. ${ }^{5}$ Following an extensive literature search, 30 primary studies (Appendix A) were located that provide estimates of pass-through rates for one or more beverages, including 15 academic articles and 15 unpublished studies in the "grey literature" (6 working papers, 5 dissertations and masters theses, 4 consulting reports). ${ }^{6}$ Studies were published beginning in 1962 [22], with a median year of 2012. The median year for data is 1999. Sixteen studies provide evidence for the U.S. and 14 studies cover a variety of other countries including western European nations (Belgium, Denmark, Finland, France, Ireland, United Kingdom); eastern European nations (Hungary, Latvia, Slovenia); groups of countries (EU, OECD); and two other nations (Japan, South Africa).

4 Griffith et al. [16:21] note that optimal tax calculations "assume that the pass-through of the tax is complete ... [but] relaxing this assumption would require modifying the optimal tax problem."

5 De Long and Lang [20:1271] is an early statement of the need to report confidence intervals as well as significance tests on point estimates. They argue that most null hypotheses in economics are rejected, so the important issue is the "ranges of parameter values that are excluded by empirical estimates." See also Romer [21].

6 Four main literature sources were searched: JSTOR; PubMed; IDEAS/RePEc; and Google Scholar. In addition, searches were conducted with Dissertation Abstracts; Social Science Research Network (SSRN); and Web of Science.
A meta-analysis requires a sample of estimates and their standard errors as a measure of "quality" or precision. A best-set approach is used. The sample consists of 76 pass-through rates for alcohol taxes, including 40 estimates for beer, 9 for wine, and 27 for spirits. Due to the small sample for wine, estimates for wine and spirits are combined. ${ }^{7}$ These estimates are selected from 24 of 30 studies but constitute only a sample of reported rates. Eight primary studies report more than 40 estimates each and two of these studies report more than 90 estimates each. Meta-analysis offers little guidance about which estimates are comparable or statistically independent, and a common criticism is that analysts often combine "apples and oranges" [3: 379]. In order to obtain comparable and meaningful estimates, the sample was selected using the following criteria: first, estimates are excluded if standard errors are missing or if a tax elasticity is reported rather than a rate. Second, some excluded estimates are unique or disparate including a singular study reporting negative rates; rates for narrowly-defined price categories or beverage types (e.g., budget-priced beer); and rates for narrowly-defined geographic areas (e.g., border areas). ${ }^{8}$ The number of estimates for narrower categories is too small to permit separate quantitative analysis. Third, estimates are selected to represent independent estimates, such as state or federal taxes but not multiple rates for state taxes in the same study. Overall, a restricted sample is more likely to cover comparable data and populations, but the sample also could reduce dispersion or publication bias. ${ }^{9}$ However, as shown below the data are consistent with a diverse sample of effect sizes.

Formally, in a meta-analysis there are $n$ estimates of the population effect that are assumed to be independent. In a FES model, the true effect-size is given by $\beta$ and the estimate reported in the $i$-th study is denoted by $Y_{i}$, with a standard error $s_{i}$ and precision $1 / s_{i}$. The model assumes observed estimates are generated by $Y_{i}=\beta+e_{i}$, where $e_{i}$ is a sampling error with mean zero and variance $\sigma^{2}$. Fixed-effect weights are defined as $w_{i}=1 / s_{i}^{2}$. As summary statistics, the FES weighted-mean and variance [25] are given by:

$$
\bar{\beta}_{F}=\sum w_{i} Y_{i} / \sum w_{i}, \quad \tilde{\sigma}_{F}^{2}=1 / \sum w_{i} \quad i=1, \ldots, n
$$

with the $95 \%$ confidence interval given by $C I_{F}=\bar{\beta}_{F} \pm$

7 Estimating separate pass-through rates by beverage is a feature of all primary studies, although some studies consider only one or two beverages. Several major wine-producing countries do not tax wine, which limits the estimates.

8 The absence of "negative" estimates in an empirical literature is frequently mentioned as an indicator of publication bias, but it could mean either insignificant (null) estimates or estimates with significant negative signs. In this analysis, it is the latter but the primary study in question [23] is unique in estimating a model with both sales taxes and excise taxes for two leading beer brands (Bud Light, Miller Lite). They argue that pass-through of excise taxes is negative because consumers "overreact" to tax increases.

9 Rhodes [24: 27$]$ notes that "the meta-analyst defines the population . . basically, definition of the population is driven by the need to average estimated effect sizes across studies, so the meta-analyst avoids averaging across treatments that differ greatly from each other." 
$t^{.05}\left(\tilde{\sigma}_{F}\right)$. Alternatively, the RES model assumes each estimate is a draw from a distribution of true effects. Thus, a RES analysis is designed to facilitate unconditional inferences about (non-sampled) studies that are similar but not identical to sampled studies [2]. Heterogeneity among underlying populations is modeled by $Y_{i}=\beta_{0}+u_{i}$, where $\beta_{0}$ is a grand effect and $u_{i}$ is an error term with mean zero and variance $\tau^{2}$. Hence, random-effects assume that observed estimates are generated by $Y_{i}=\beta_{0}+u_{i}+e_{i}$, where errors are assumed to be independent. The estimated variance of each primary effect is given by a composite error term, $V_{i}^{2}=s_{i}^{2}+T^{2}$, where $T^{2}$ is an estimate of variation in true effects around the grand mean. Note there is only one value of $T^{2}$ for all estimates in a sample, but there are several possible methods for obtaining an estimate with method-of-moments used here (DerSimonian-Laird method). The RES weighted-mean and variance are given by equation (2), with an estimate of the grand mean denoted by $\bar{\beta}_{R}$ and weights $w_{i}{ }^{*}=1 / V_{i}^{2}$ :

$$
\bar{\beta}_{R}=\sum w_{i}^{*} Y_{i} / \sum w_{i}^{*}, \quad \tilde{\sigma}_{R}^{2}=1 / \sum w_{i}^{*} \quad \mathrm{i}=1, \ldots, \mathrm{n}
$$

with the $95 \%$ confidence interval given by $C I_{R}=\bar{\beta}_{R} \pm$ $t^{.05}\left(\tilde{\sigma}_{R}\right)$, which shows the precision of the mean. The $95 \%$ prediction interval is given by $P I_{R}=\bar{\beta}_{R} \pm t .05 \sqrt{T^{2}+\tilde{\sigma}_{R}^{2}}$, which quantifies the dispersion of the mean estimate and the estimated variance of true effects [14]. The variance of true effects does not approach zero as estimates increase in number.

As a third measure, Thompson and Sharp [26] propose a "weighted least-squares" (WLS) estimator that incorporates residual heterogeneity with weights proportional to inverse effect variances. Stanley and Doucouliagos [27] suggest the WLS-estimator is superior to standard FES and RES-estimators. First, they argue that fixed-effect confidence intervals are too small if applied to unconditional inferences since the assumption is that estimates are a sample from a homogeneous population $\left(\tau^{2} \approx 0\right)$. Second, they argue that random-effects are sensitive to estimates of $\tau^{2}$ if the sample is small or suffers from publication bias. They propose instead a WLS-estimator with weights given by $w_{i}^{\prime}=1 /\left(\phi s_{i}^{2}\right)$, where $\phi>1$ is a proportionality constant. The WLS-estimator produces the same mean as a FES-estimator, but its variance is different, i.e., $\tilde{\sigma}_{L}^{2}=$ $\phi /\left(\sum w_{i}\right)=\phi \tilde{\sigma}_{F}^{2}$ [27: 2117]. An appropriate estimate of $\phi$ can be obtained from the mean squared error from an OLS regression of standardized effect sizes $\left(t_{i}=Y_{i} / s_{i}\right)$ on their precision. Alternatively, a comparable measure is the $\mathrm{H}^{2}$ statistic for overdispersion [26: 2699]. The $\mathrm{H}^{2}$ statistic is obtained by dividing Cochrane's Q-statistic by $\mathrm{n}-1$. To obtain WLS standard errors, FES standard errors are multiplied by $\sqrt{ } \phi=H$. However, because $\phi$ is derived from the Q-statistic, it potentially suffers from the same imprecision problem that arises in estimating $\tau^{2}$ from small samples.

\subsection{Results for Weighted Means and Heterogeneity Tests}

Table 1 summarizes the sample together with unweighted averages for several subgroups and confidence intervals. The range of estimates is substantial, arising from several possible sources including sampling error, data type, econometric methods, heterogeneous populations, outliers, and publication bias. Unweighted averages indicate pass-through rates are greater than unity and more substantial for the beer subgroup. The histogram in Figure 1 also indicates a broad range of effect sizes, although most estimates are clustered in the range 0.5 to 1.5. For the full sample $(n=76)$, Table 2 displays results for FES, WLS, and RES-means, together with statistical measures for dispersion and heterogeneity. The FES-mean for alcohol is 1.04 . The $95 \%$ confidence interval is reasonably narrow and barely exceeds unity, 1.02 to 1.07 . The wider confidence interval for the WLS-mean is 0.99 to 1.10. The RES-mean gives greater weight to less precise estimates. ${ }^{10}$ The RES-mean for alcohol is 1.16 and the confidence interval is 1.09 to 1.24 , suggesting on average there is overshifting of taxes. The prediction interval is 0.69 to 1.64 , consistent with both under- and overshifting of taxes. Heterogeneity statistics in Table 2 indicate substantial sample dispersion, suggesting use of the RES model:

- Cochrane's Q-statistic. The Q-statistic is a standardized measure of dispersion or weighted sum of squared deviations (WSS), i.e., deviation of each primary effect from the FES-mean, weighted by the inverse-variance of that effect and summed over all values in the sample. $\mathrm{Q}$ measures total dispersion around the mean and $\mathrm{Q}-\mathrm{df}$ is residual or "excess dispersion," where $d f=(n-1)$ is degrees of freedom. If there is a common effect size, then $Q=d f$. Under a null hypothesis of a common effect, $Q$ has a chi-square distribution with $n-1$ degrees of freedom. The $\mathrm{p}$-value in Table 2 indicates the null is rejected for $\mathrm{n}=76$ at the $95 \%$ confidence level. Power for the Q-statistic is discussed in [3, 24].

- H-statistic. $\mathrm{H}^{2}=\mathrm{Q} /(\mathrm{df})$ is the ratio of observed WSS to expected WSS if there is a common effect. Thus, $\mathrm{H}$ $=1$ when there is homogeneity of effect sizes, which is rejected in Table 2.

- I-squared. This statistic equals $((\mathrm{Q}-\mathrm{df}) / \mathrm{Q}) \times 100 \%=$ $\left(\left(\mathrm{H}^{2}-1\right) / \mathrm{H}^{2}\right) \times 100 \%$, which is a ratio of excess dispersion to total dispersion. $\mathrm{I}^{2}$ is thus analogous to 1 - $\mathrm{R}^{2}$ for regressions. In general, an $\mathrm{I}^{2}$ less than $25 \%$ is

10 Weights in the FES and RES models are substantially different. Raw weights in the FES model vary from 625.0 for the most precise estimate to 0.36 for the least precise, with a median weight of 14.8. Relative weights vary from $9.44 \%$ to $0.005 \%$, with a median of $0.22 \%$. For the RES model, raw weights vary from 17.5 to 0.36 , with a median weight of 8.12 . Relative weights vary from $2.57 \%$ to $0.05 \%$, with a median of $1.19 \%$. These differences are typically not mentioned in prior meta-analyses in economics. 
considered low relative dispersion; $25-75 \%$ is moderate dispersion; and greater than $75 \%$ is high dispersion [30]. The Table 2 value of $82 \%$ indicates high dispersion. Values of $75-95 \%$ are common in economics studies.

- T-squared. This statistic is the sample estimate of the variance of true effect sizes $\left(\tau^{2}\right)$, which is used to assign weights in the RES model. Larger values of T or $\mathrm{T}^{2}$ are indicative of greater dispersion. In Table 2, the standard error for $\mathrm{T}^{2}$ is 0.019 , which indicates that $95 \%$ of values are likely to lie in the range 0.018 to 0.092, with a mean of 0.055. Conventional confidence intervals are reported.

- 95\% Prediction interval. This statistic combines information about the variance of the mean effect $\left(\mathrm{se}^{2}\right)$ and the variance of true effects $\left(\mathrm{T}^{2}\right)$. For mean effects, the confidence interval (CI) quantifies the accuracy of estimated means, but the prediction interval (PI) shows the potential distribution of true effects [3: 131]. The prediction interval is the measure of heterogeneity that best captures possible dispersion of true effects [1: 100]. It is a more conservative measure of results in a meta-analysis. The PI range in Table 2 includes unity but does not rule out either under- or overshifting of taxes.

The RES prediction interval in Table 2 is substantial, indicating that pass-through rates for alcohol beverages can be greater or less than unity. In contrast, the confidence interval for the FES model exceeds unity by only a modest amount. The WLS confidence interval includes unity, so the three models offer different results. Although dispersion statistics are not commonly reported in meta-analyses conducted in economics, it seems likely the estimates in Table 2 are not unrepresentative of economic data generally. Most primary samples in economics reflect a wide range of data and empirical methods, making assumption of a common effect size untenable [13]. If inferences are restricted conditionally as in the case of fixed-effects, the problem is partially solved. However, the danger is that analysts or readers generalize results or seek to make inferences that go beyond the conditional population such as required by policy applications. Several alternatives are available to address issues of excess dispersion and random heterogeneity. First, the analyst might choose to abandon meta-analysis and conduct instead a traditional narrative review of the literature. Second, the analyst could utilize subgroups of estimates where assumption of a common effect may be defensible. Third, the analyst can estimate meta-regressions, including covariates that control for observable systematic differences. This is the methodology commonly chosen in economics, although it needs to be emphasized that either FES or RES models can be applied in a meta-regression.

Table 1. Summary statistics for alcohol tax pass-through rates

\begin{tabular}{|c|c|c|}
\hline Sample \& statistic & Value (sd) & $\begin{array}{l}\text { 95\% Confidence } \\
\text { interval }\end{array}$ \\
\hline \multicolumn{3}{|l|}{$\begin{array}{c}\text { Alcohol tax sample }(\mathrm{n}= \\
76)\end{array}$} \\
\hline Unwt. mean rate (sd) & $1.41(0.69)$ & $0.06-2.76$ \\
\hline Median rate & 1.20 & \\
\hline Range & $0.56-3.84$ & \\
\hline $\begin{array}{l}\text { Unwt. mean std error } \\
\qquad(\mathrm{sd})\end{array}$ & $0.34(0.30)$ & \\
\hline Unwt. mean t-stat. (sd) & $7.62(6.55)$ & \\
\hline \multicolumn{3}{|l|}{ U.S. subgroup $(n=45)$} \\
\hline Unwt. mean rate (sd) & $1.45(0.65)$ & $0.18-2.72$ \\
\hline Median & 1.41 & \\
\hline Range & $0.56-3.19$ & \\
\hline \multicolumn{3}{|l|}{ Beer subgroup $(n=40)$} \\
\hline Unwt. mean rate (sd) & $1.57(0.81)$ & $-0.02-3.16$ \\
\hline Median & 1.34 & \\
\hline Range & $0.56-3.84$ & \\
\hline \multicolumn{3}{|l|}{$\begin{array}{l}\text { Published subgroup ( } \mathrm{n} \\
=30)\end{array}$} \\
\hline Unwt. mean rate (sd) & $1.43(0.58)$ & $0.29-2.57$ \\
\hline Median & 1.28 & \\
\hline Range & $0.62-3.00$ & \\
\hline
\end{tabular}

Notes: standard deviations (sd) in parentheses.

Table 2. Fixed and random-effects means - Alcohol tax pass-through rates

\begin{tabular}{cccc}
\hline $\begin{array}{c}\text { Sample } \& \\
\text { statistic }\end{array}$ & Value (se) & $\mathbf{9 5 \%}$ CI & 95\% PI \\
\hline Alcohol taxes (n & & & \\
= 76) & & & \\
FES mean & 1.044 & $1.020-1.068$ & \\
& $(0.012)$ & & \\
WLS mean & 1.044 & $0.989-1.100$ & \\
& $(0.028)$ & & \\
RES mean & 1.164 & $1.089-1.238$ & $0.698-1.630$ \\
& $(0.038)$ & & \\
Q-stat. (p-value) & 422.7 & & \\
H-stat. & $(0.000)$ & & \\
I-sq. \% & 2.37 & $2.14-2.62$ & \\
T-sq. (se) & 82.3 & $78.3-85.5$ & \\
\hline
\end{tabular}

Notes: Method-of-moments used for random-effects $\mathrm{T}^{2}$. All statistics computed in Comprehensive Meta Analysis 3 [28]. Basic results checked against Stata 16. $\mathrm{CI}=$ confidence interval. $\mathrm{PI}=$ prediction interval. $\mathrm{se}=$ standard error. Formula for I-sq. confidence interval using Q is from [3: 124]. Formula for a test-based $H$ confidence interval using $Q$ is from [29:1554]. Conventional confidence interval used for $\mathrm{T}^{2}$ based on sample sizes. 
Fixed-Effect versus Random-Effects Meta-Analysis and Meta-Regressions

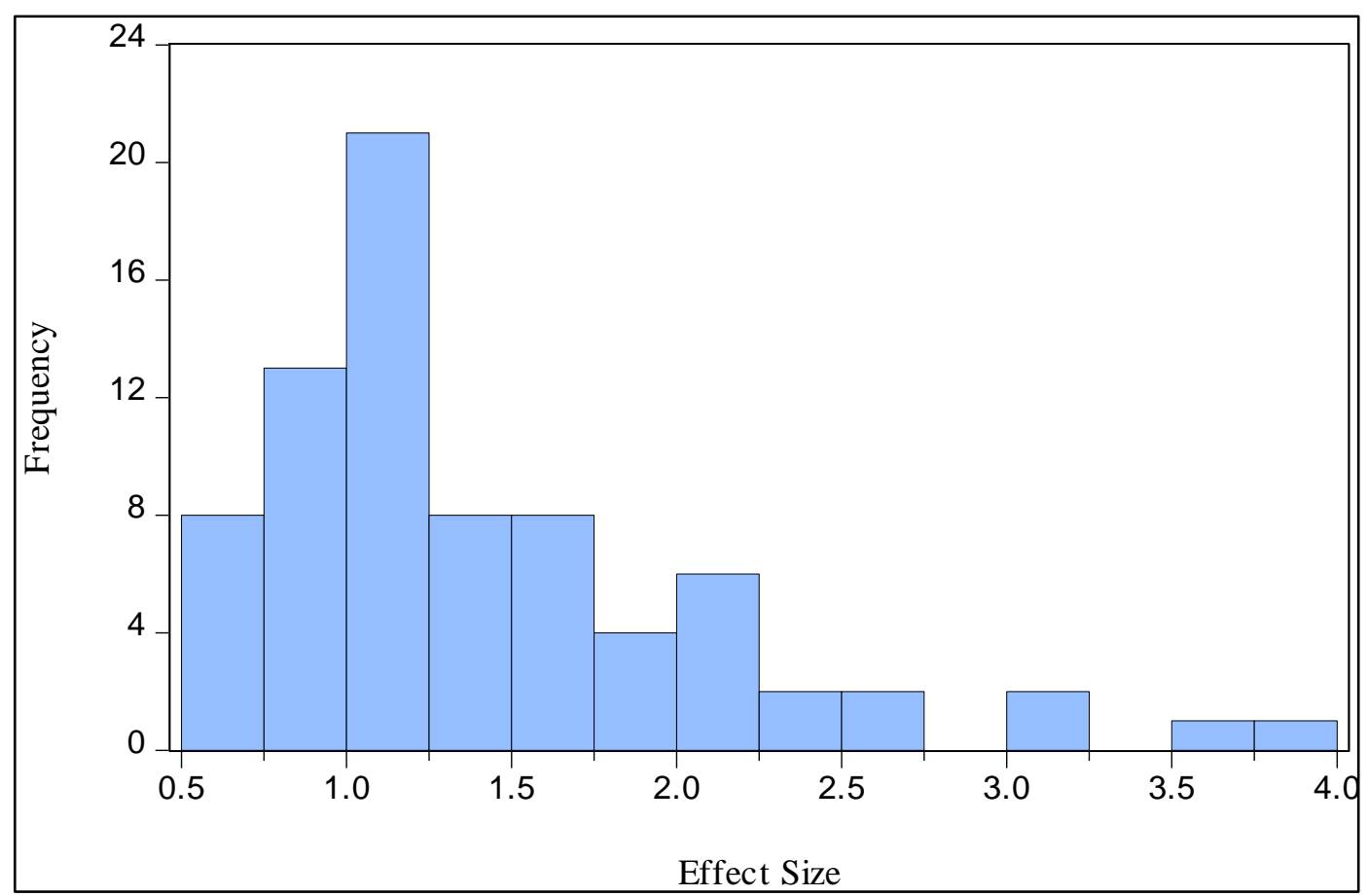

Figure 1. Histogram of alcohol tax pass-through rates $(n=76)$

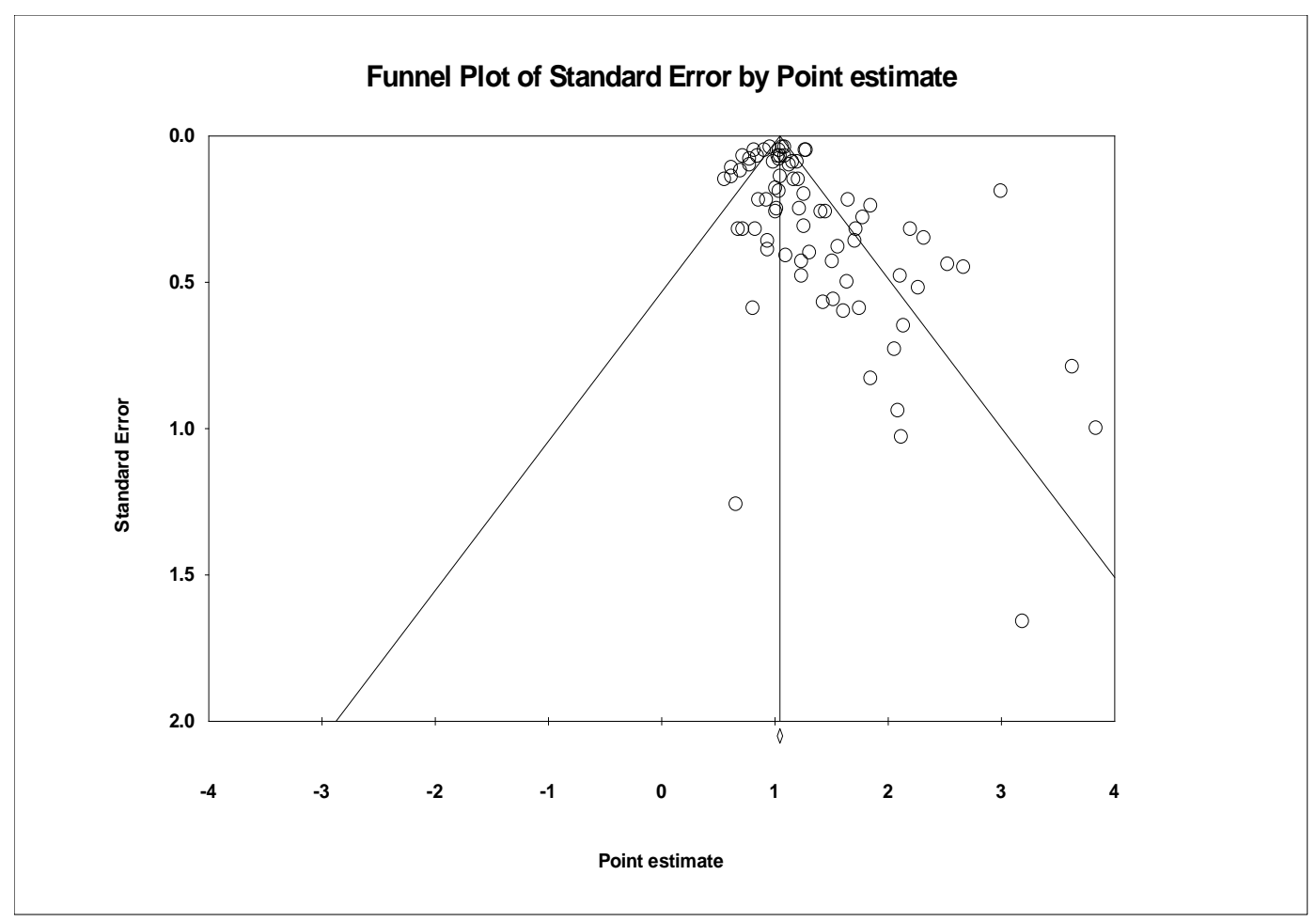

Figure 2a. Funnel plot of pass-through rates and standard errors $(n=76)$ 


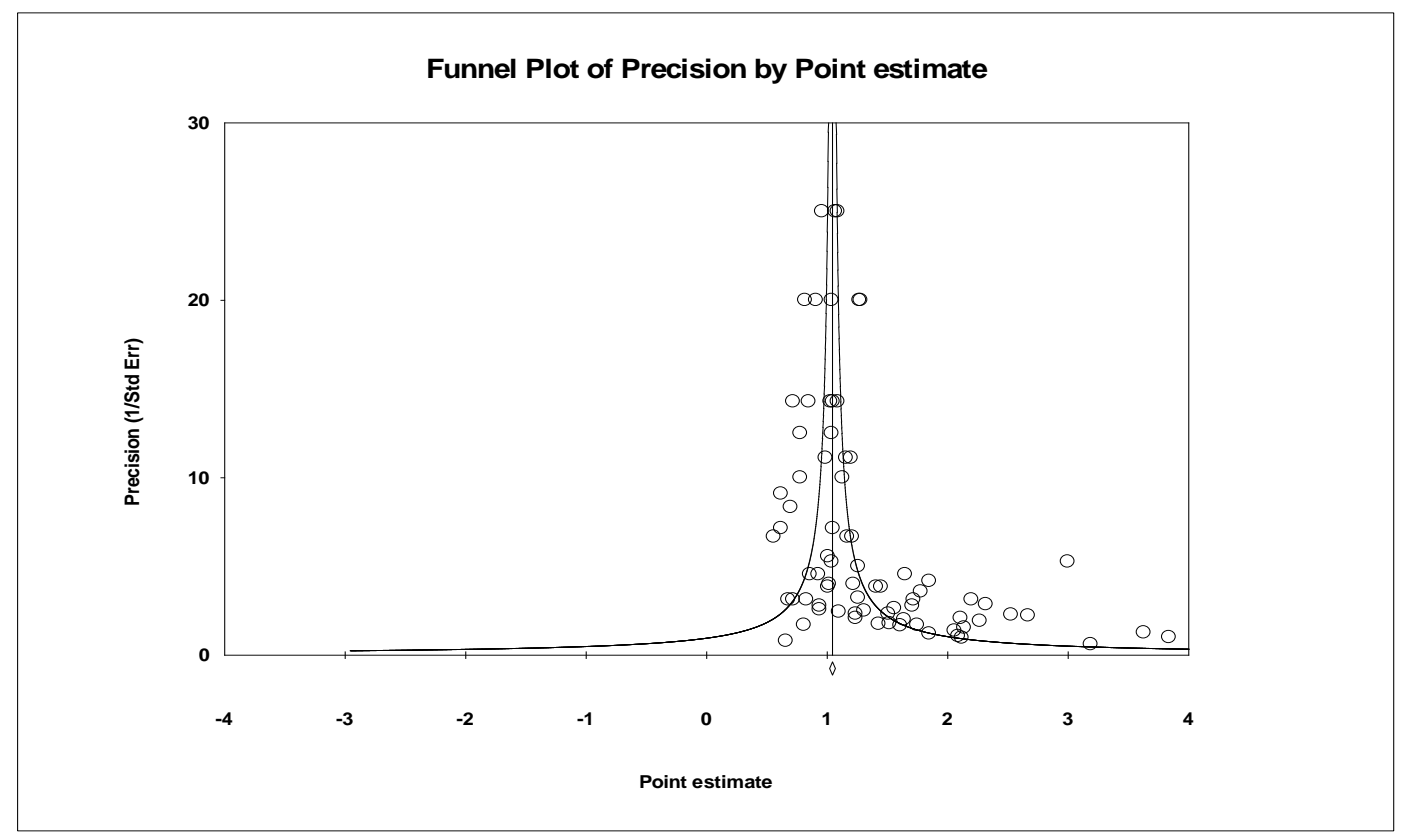

Figure 2b. Funnel plot of pass-through rates and precisions $(n=76)$

\section{Subgroup Analysis Results: Countries, Beverages, and Publication Status}

Identifying subgroups within a sample is one possible solution to issues of excess dispersion, where the primary estimates within each subgroup share a well-defined characteristic. If estimates within a subgroup are homogeneous, use of the FES model is correct for that group. In the ideal scenario, there is homogeneity in each subgroup and inferences using means for each group are possible. Mean effects across subgroups can be compared or combined, which can add to insights from the analysis. Hence, meta-analysis of subgroups is often conducted using ANOVA methods. Further, the RES model requires calculation of $\mathrm{T}^{2}$, but the analyst has a choice of whether to pool subgroup estimates or not. Given dispersion within subgroups, it is assumed that estimates within a subgroup are random, but subgroups are fixed, i.e., the pooled model is based on mixed-effects size (MES) that permits generalizations to comparable populations [1: 196]. This section reports meta-analyses for three categories of subgroups: (1) country source (U.S. vs. not-U.S. rates); (2) beverage type (beer vs. wine-spirits); and (3) publication status (published vs. not-published studies). Pooled estimates are compared to the RES-mean value in Table 2.

Table 3 displays results for subgroup analysis. First, there is more dispersion for the U.S. subgroup as indicated by RES-means. However, $\mathrm{I}^{2}$ values for both subgroups are substantial, $74 \%$ and $88 \%$. The prediction interval for the
U.S. subgroup is larger, but Q-statistics reject homogeneity within subgroups. Second, the beer subgroup is highly dispersed as indicated by $\mathrm{I}^{2}$ of $84 \%$; the $95 \%$ prediction interval, 0.35 to 2.26; FES-mean compared to the RES-mean, 1.14 vs. 1.30 ; and $\mathrm{T}^{2}$ equal to 0.223 . The wine-spirits subgroup is somewhat less dispersed. Third, published studies also exhibit a greater degree of dispersion. The $\mathrm{I}^{2}$ value is $87 \%$ and the $95 \%$ prediction interval is 0.57 to 1.97. RES-means for published and unpublished studies differ substantially, 1.27 compared to 1.10. Fourth, pooled MES-means do not differ much from the RES-mean in Table 2, 1.164-1.168 compared to 1.164 . Fifth, most confidence intervals for subgroups means in Table 2 include unity. There are 14 of 18 confidence intervals that include unity or are close to that value (e.g., 1.01). Exceptions include RES intervals for U.S.-based estimates, beer, and published studies. This helps identify subgroups with larger and less precise estimates, a possible indicator of publication bias. All prediction intervals include unity, but ranges are substantial. All within-group Q-statistics reject homogeneity, which is a common outcome in similar analyses. However, it is well-known that tests based on Q have low power, so it is important to consider a variety of tests and procedures. Lastly, all subgroup prediction intervals include unity, but the intervals are quite wide for U.S.-based estimates, beer, and published studies. Full-shifting of taxes is possible, but either under- or overshifting cannot be ruled out at this stage. Further tests are required. 
Table 3. Fixed and random-effects meta-analysis - Subgroup analysis

\begin{tabular}{|c|c|c|c|}
\hline Subgroup \& statistic & Value (se) & $95 \% \mathrm{CI}$ & $95 \%$ PI \\
\hline \multicolumn{4}{|l|}{ US estimates $(n=45)$} \\
\hline FES mean & $1.056(0.023)$ & $1.011-1.100$ & \\
\hline WLS mean & $1.056(0.045)$ & $0.968-1.144$ & \\
\hline RES mean & $1.257(0.059)$ & $1.141-1.372$ & $0.698-1.816$ \\
\hline Within Q-stat. (p-value) & $167.4(0.000)$ & & \\
\hline H-stat. & 1.95 & $1.69-2.26$ & \\
\hline I-sq. $\%$ & 73.7 & $64.9-80.3$ & \\
\hline T-sq. & $0.078(0.051)$ & $-0.02-0.178$ & \\
\hline \multicolumn{4}{|l|}{ Not-US estimates $(\mathrm{n}=31)$} \\
\hline FES mean & $1.039(0.015)$ & $1.010-1.067$ & \\
\hline WLS mean & $1.039(0.044)$ & $0.953-1.125$ & \\
\hline RES mean & $1.099(0.052)$ & $0.996-1.201$ & $0.641-1.557$ \\
\hline Within Q-stat. (p-value) & $254.8(0.000)$ & & \\
\hline H-stat. & 2.91 & $2.53-3.35$ & \\
\hline I-sq. $\%$ & 88.2 & $84.4-91.1$ & \\
\hline T-sq. & $0.052(0.021)$ & $0.011-0.093$ & \\
\hline Pooled MES mean & $1.168(0.039)$ & $1.091-1.245$ & $0.702-1.634$ \\
\hline \multicolumn{4}{|l|}{ Beer estimates $(n=40)$} \\
\hline FES mean & $1.137(0.031)$ & $1.076-1.199$ & \\
\hline WLS mean & $1.137(0.078)$ & $0.984-1.290$ & \\
\hline RES mean & $1.304(0.059)$ & $1.188-1.420$ & $0.351-2.257$ \\
\hline Within Q-stat. (p-value) & $245.2(0.000)$ & & \\
\hline H-stat. & 2.51 & $2.19-2.87$ & \\
\hline I-sq. $\%$ & 84.1 & $79.2-87.8$ & \\
\hline T-sq. & $0.223(0.096)$ & $0.035-0.411$ & \\
\hline \multicolumn{4}{|l|}{ Wine-spirits $(\mathrm{n}=36)$} \\
\hline FES mean & $1.027(0.013)$ & $1.001-1.053$ & \\
\hline WLS mean & $1.027(0.028)$ & $0.972-1.082$ & \\
\hline RES mean & $1.063(0.050)$ & $0.965-1.161$ & $0.738-1.388$ \\
\hline Within Q-stat. (p-value) & $167.0(0.000)$ & & \\
\hline H-stat. & 2.18 & $1.87-2.54$ & \\
\hline I-sq. $\%$ & 79.0 & $71.6-84.6$ & \\
\hline T-sq. & $0.025(0.011)$ & $0.003-0.047$ & \\
\hline Pooled MES mean & $1.164(0.038)$ & $1.089-1.239$ & $0.698-1.630$ \\
\hline \multicolumn{4}{|l|}{ Published studies $(\mathrm{n}=30)$} \\
\hline FES mean & $1.051(0.024)$ & $1.004-1.097$ & \\
\hline WLS mean & $1.051(0.067)$ & $0.920-1.182$ & \\
\hline RES mean & $1.273(0.062)$ & $1.152-1.394$ & $0.572-1.974$ \\
\hline Within Q-stat. (p-value) & $224.6(0.000)$ & & \\
\hline H-stat. & 2.78 & $2.40-3.22$ & \\
\hline I-sq. $\%$ & 87.1 & $82.7-90.4$ & \\
\hline T-sq. & $0.124(0.062)$ & $0.002-0.246$ & \\
\hline
\end{tabular}




\begin{tabular}{|c|c|c|c|}
\hline Table 3 (continued) & Value (se) & $95 \% \mathrm{CI}$ & $95 \%$ PI \\
\hline \multicolumn{4}{|l|}{ Unpublished $(\mathrm{n}=46)$} \\
\hline FES mean & $1.041(0.014)$ & $1.013-1.069$ & \\
\hline WLS mean & $1.041(0.029)$ & $0.984-1.098$ & \\
\hline RES mean & $1.097(0.050)$ & $0.999-1.195$ & $0.722-1.471$ \\
\hline Q-stat. (p-value) & $198.0(0.000)$ & & \\
\hline H-stat. & 2.10 & $1.83-2.41$ & \\
\hline I-sq. $\%$ & 77.3 & $70.0-82.8$ & \\
\hline T-sq. & $0.034(0.016)$ & $0.003-0.065$ & \\
\hline Pooled MES mean & $1.167(0.039)$ & $1.091-1.243$ & $0.701-1.633$ \\
\hline
\end{tabular}

Notes: See notes for Table 2. RES-means calculated using a mixed-effects size (MES) model for subgroups. The estimate of the sample variance ( $\mathrm{T}^{2}$ ) is assumed to be the same for all subgroups, i.e., a value is computed within subgroups and then pooled across subgroups using fixed-effects to obtain the estimate. RES-means for beer and wine-spirits differ from those in Table 5 due to assumptions of the MES model. Between-group Q-statistics (p-value) for fixed and random-effects are: (1) country source, 4.10 (0.043) and $11.2(0.001)$; (2) beverage type, 10.5 (0.001) and 9.66 (0.002); and (3) publication status, $0.119(0.730)$ and $4.90(0.027)$.

\section{Detecting and Reducing Publication Bias: Tax Pass-Through Rates}

\subsection{Detecting Publication Bias: Funnel Plots and Regression Asymmetry Tests}

Publication or reporting bias is now recognized as a major issue in many areas of scientific inquiry, including applied economics [20, 31-36]. Bias is important because it can lead to incorrect conclusions for a narrative review or quantitative analysis, including false positives or Type 1 errors. Publication bias is generally understood to have two important dimensions, both of which tend to exaggerate reported estimates of effect sizes. First, non-publication of weak, null, or contrary results, which is known as the "file-drawer problem." Second, a tendency for scientific journals to publish statistically significant results and avoid "negative results," resulting in data-mining by primary researchers ("p-hacking"), i.e., significant findings are more likely to be published causing bias as researchers mine their data to find publishable estimates. The first problem can be addressed in part by a thorough search of the literature, which is greatly aided by web-based resources. The data-mining issue requires, first, detecting publication bias in a sample of primary estimates and, second, application of methods to reduce bias and obtain corrected estimates for mean effect sizes. This section presents two methods to detect publication bias (funnel plots, Egger's funnel asymmetry test) and three methods to reduce publication bias (trim-and-fill, cumulative meta-analysis, meta-regressions). Meta-regression results include predicted means and confidence intervals. Results are reported for the full sample and selectively by beverage for both fixed- and random-effects models.

Figure 2 shows funnel plots of effect sizes plotted against standard errors (2a) or precision (2b), with a vertical line for the FES-mean. In the absence of publication bias, effect sizes will be distributed symmetrically about the mean. Funnel-shaped lines represent 95\% confidence intervals for between-study variation, i.e., in the absence of heterogeneity $95 \%$ of all estimates would lie within these lines. Both plots suggest "missing" values to the left of the mean, but this could be due to publication bias, study-level heterogeneity, or causal factors such as imperfect markets for alcohol. The plots also indicate that larger estimates tend to have larger standard errors reflecting natural heteroskedasticity in meta-data. ${ }^{11}$ More precise estimates in Figure 2 are clustered at the top of funnel plots in the range 0.5 to 1.5 .

An alternative to visual inspection of plots is Egger's regression test for asymmetry, obtained by regressing standardized effect sizes $\left(t_{i}=Y_{i} / s_{i}\right)$ on corresponding FES precision $\left(1 / s_{i}\right)$ and an intercept. In economics, this is referred to as a funnel asymmetry test (FAT); see [37: 61]. In the presence of publication bias, the intercept is significantly different from zero and the slope coefficient is a biased-adjusted estimate of the FES-mean, i.e., a precision-effect test (PET). Further, Stanley and Doucouliagos [37: 65] propose adding effect-size standard errors $\left(s_{i}\right)$ to the FAT regression in order to capture non-linearities, which they label the precision effect estimate with standard error (PEESE). It should be emphasized that standard errors are themselves estimates, so all meta-regression tests are possibly biased [38]. Lin and $\mathrm{Chu}$ [39] propose another modified version for samples with significant heterogeneity, where the effect size is divided by the RES standard error and the covariate is the RES-adjusted precision. Table 4 displays results for the three tests for asymmetry, where indicators of bias are intercept terms and the slope coefficient on the standard error variable in the PEESE regression. All three terms are significantly positive, consistent with selection bias. Precision coefficient values and confidence intervals for

11 Effect sizes and standard errors are positively correlated. For alcohol, the simple correlation is 0.595 ; beer, 0.515 ; and wine-spirits, 0.707 . 
PET and PEESE regressions provide support for the null hypothesis of unity. Lin-Chu's test performs poorly, although the dependent variable is different.

\subsection{Selection Corrections: Trim-and Fill Results}

Having detected the possible presence of publication bias, the next issue is what to do about it or how to correct mean effects for bias in FES and RES models. Three main methods are available. The first is the "trim-and-fill" procedure due to Duval and Tweedie [40], which is an iterative procedure that identifies those estimates responsible for asymmetry in Figure 2 and fills the plot with mirror-images of the outlying estimates. Adjusted-mean values are computed using the filled-sample of estimates. Both FES and RES-means can be recomputed using either unadjusted mean as a base to detect missing values, but FES-base means are traditionally used and employed here as well. The following results are obtained for trim-and-fill:

- Trim-and-fill FES-means. The adjusted FES-mean for all alcohol beverages is $1.018(0.026)$, with a $95 \%$ confidence interval of $0.967-1.069$. Adjusted FES-mean for beer is $1.012(0.030)$, with a $95 \%$ confidence interval of $0.953-1.071$. Adjusted FES-mean for wine-spirits is $1.022(0.013)$, with a 95\% confidence interval of $0.996-1.048$. The three confidence intervals include unity, consistent with the null hypothesis. Mean values are close to one.

- Trim-and-fill RES-means. The adjusted RES-mean for all alcohol beverages is 1.019 (0.042), with a $95 \%$ confidence interval of 0.937 to 1.101 . Adjusted RES-mean for beer is 1.063 (0.104), with a 95\% confidence interval of $0.859-1.267$. Adjusted RES-mean for wine-spirits is $1.008(0.038)$, with a $95 \%$ confidence interval of $0.934-1.082$. The three confidence intervals include unity, consistent with the null hypothesis. Mean values are close to one, but larger for beer.

\subsection{Selection Corrections: Cumulative Meta-Analysis Results}

The second method for reducing publication bias is based on a cumulative meta-analysis [3: 287]. Effect estimates are ordered in ascending size of standard errors. Sequentially, estimates are included in the sample yielding cumulative means that vary as less precise values are added. In the presence of selection bias, the expectation is that mean values will increase as the sample is expanded to include less precise values. Table 5 and Figure 3 show the results for three cumulative meta-analyses for all alcohol and each beverage. Four or five cumulative means and relative weights are reported for each array. For all alcohol beverages, the FES-mean rises only slightly but most of the weight in the analysis is on a small portion of the total sample. The first 15 estimates have a relative weight of $79 \%$. Results for the RES model are revealing as the last 21 estimates increase the mean from 1.07 to 1.16. The first three RES confidence intervals include unity, but the final interval $(n=76)$ does not. The first 30 estimates yield equal mean values for FES and RES models, 1.023, and then diverge as shown in Figure 3. For beer, FES and RES-means for the first 20 estimates are 1.085 and 1.216. The sample of beer estimates is skewed toward larger and less precise values, which has a greater impact on the RES-mean. In contrast, mean values for wine-spirits for the first 20 estimates are 1.022 and 1.005 , indicating pass-through rates that barely exceed unity regardless of model. Overall, a cumulative analysis suggests average rates of unity, except beer. For all alcohol, the 21 least precise estimates strongly affect the RES-mean. For beer, the RES-mean rises sharply after the first 10 estimates. Similar patterns are not found for FES-means or the wine-spirits subgroup. Except beer, median weighted-rates are approximately unity: 1.028 and 1055; and 1.021 and 0.998 . The beer rates are 1.085 and 1.216. A cumulative analysis also illustrates potential problems inherent in both fixed and random-effects models. The FES model gives substantial weight to more precise estimates, which may not be representative of the population of interest or could be due to outliers. The RES model gives more weight to less precise estimates, but weak precision can be due to publication selection bias. Estimation of the between-study variance also may limit a RES model. These results seem not generally recognized in economics. 


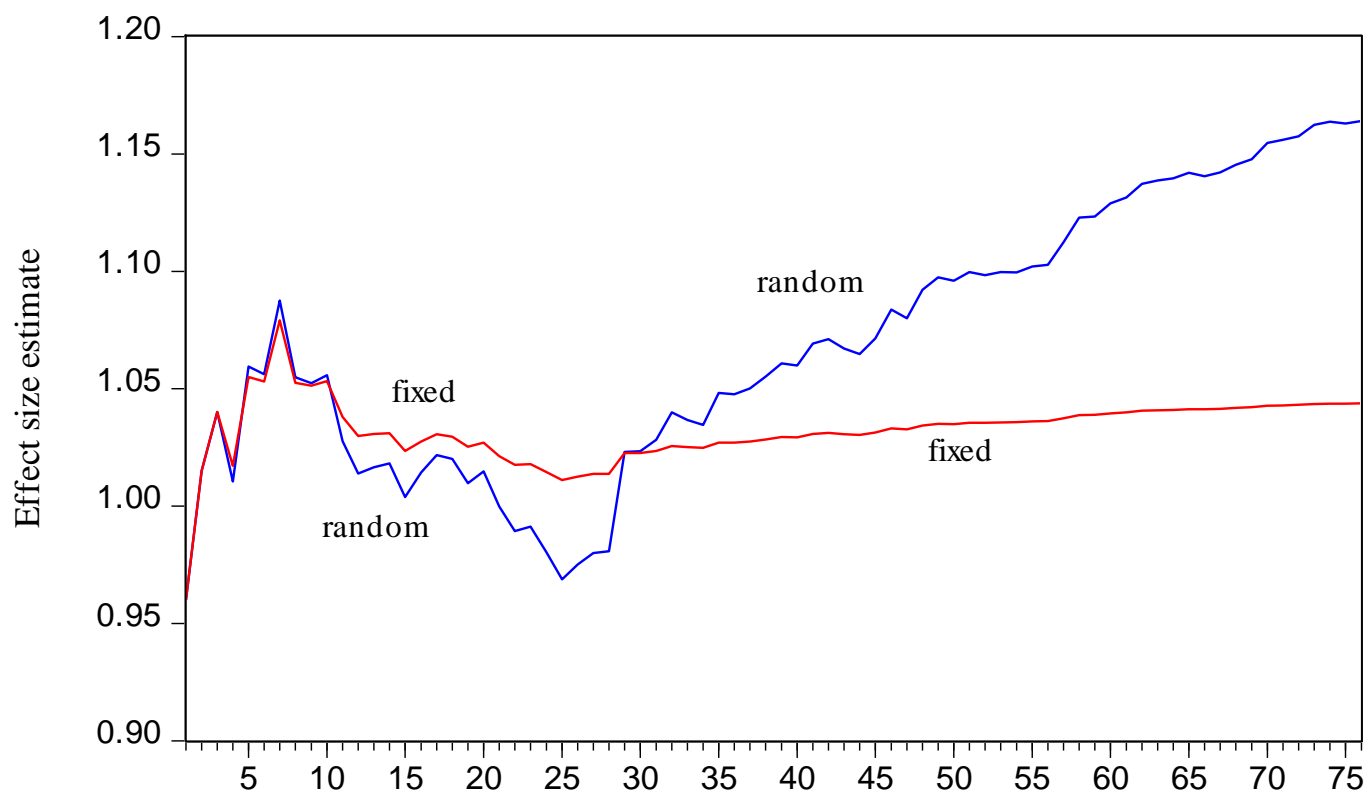

Number of observations added

Figure 3. Trace of cumulative fixed and random-effects means $(\max n=76)$

\subsection{Selection Corrections: Meta-Regressions for Fixed-Effect and Random-Effects}

The third method for reducing bias is a meta-regression analysis (MRA) that seeks to explain systematic heterogeneity and simultaneously correct or reduce publication bias. However, there is division between economists and non-economists on the appropriate regression model. In the first instance, Stanley and Doucouliagos [37] recommend using a fixed-effect model estimated by weighted least-squares with weights based on inverse variances. They argue “. . . because the standard error, or precision, is always one of the independent variables in our MRA models, a random-effects model is likely to be invalid" [37: 64]. This argument is valid, first, if covariates can explain a substantial portion of observed variation in effect sizes. ${ }^{12}$ However, as shown below, this is not the case for alcohol tax pass-through rates. Second, it must be the case that analysis is restricted to the current set of estimates and there is no desire to make unconditional inferences about broader populations. This is the standard argument in favor of random-effects. Third, it is not explained why FES weights are independent of moderators, e.g., variance inflation factors (VIF) reported below are slightly smaller for RES regressions. Fourth, Stanley and Doucouliagos [37: 85] also argue that a regression analysis should incorporate the variance as an explanatory variable (as

12 Konstantopoulos and Hedges [41: 246] argue "If a fixed-effects model explains all of the variation in effect-size parameters, the (fixed-effects) model is appropriate . . . if differences between studies that lead to differences in effects are not regarded as random ... then fixed-effects methods are appropriate" (emphasis in the original). well as the standard error). However, both variables are potentially subject to bias [36: 395]. Fifth, as shown in the cumulative analysis, a weakness of the FES model is that considerable weight might be given to a small portion of the sample, thereby limiting inferences from a regression analysis. As a result of these several considerations, other commentators recommend a random-effects model, e.g., $[1,3,42]$, with Knapp-Hartung adjustment of standard errors on RES regression coefficients [1: 36]. ${ }^{13}$ Both FES and RES regressions are reported for all alcohol and selectively by beverage. A Q-test is used to determine if FES regression estimates are consistent with trivial heterogeneity. As expected for economic data, the Q-test rejects the FES model. ${ }^{14}$

Meta-regressions can be used to control for both differences in basic data and differences in methods employed by researchers. In the case of data by beverage or country, categorical variables allow generalization to specific populations. Controls for method are observational and thus consistent with assumptions of the FES model [24]. Predicted means from regressions are reported to test the null hypothesis of a unitary pass-through. Weighted meta-regressions are obtained using Comprehensive Meta Analysis v3 software [28, 44], supplemented with Stata 16 for predicted means. Regression results are reported for seven covariates with

13 Knapp-Hartung standard errors are larger than conventional standard errors provided by, say, Stata 16, so meta-regressions reported for the RES model are conservative in this dimension; see [41]

14 Bruns [43:641] argues that the random-effects model requires "strict exogeneity" of regressors. However, he fails to provide examples where this might be violated or explain why fixed-effect meta-regressions with "many control variables" might not be more subject to this problem. 
the following expectations regarding coefficient signs (binary dummy variables, except the standard error variable):

- Standard error variable. Expected to be significantly positive in the presence of publication bias, i.e., larger standard errors are associated with larger effect sizes.

- Wine-spirits variable. Subgroup analysis indicated that mean estimates for beer might be significantly larger than those for wine and spirits. Expected coefficient sign is negative. A wine-only dummy also is defined for the nine primary observations for wine.

- Not-US variable. Subgroup analysis indicated that not-US estimates might differ systematically from US estimates, with expectation of a negative sign.

- Published study variable. Publication bias might appear as a tendency for published rate estimates to exceed those found in grey literatures, with a positive expected sign.

- OLS-estimate variable. Simple OLS generates effect-size estimates under classical assumptions that might be incorrect. Direction of bias is difficult to ascertain for all possible violations of classical assumptions. The expected sign is uncertain.

- Micro-data variable. Because estimates based on micro-data use larger sample sizes, expectations are that these estimates have smaller standard errors and potentially smaller effect sizes, ceteris paribus. The expected coefficient sign is negative.

- Real data variable. Some primary estimates are based on inflation-adjusted prices and taxes, but others are not. Nelson and Moran [6] report that primary studies estimating both real and nominal models do not find substantially different results. The expected outcome is a statistically insignificant coefficient with an uncertain sign.

Table 6 displays random and fixed-effects meta-regressions for all alcohol. All six coefficients for the standard error variable are significantly positive. The 95\% CIs for bias-corrected intercepts include unity. Subgroup dummies for country source, beverage type, and publication status are never significant. Moderators for data and method are not significant, except the OLS dummy in regression (6). However, Q-tests for heterogeneity are significant, which indicates that estimates are not consistent with assumptions of the FES model, i.e., true effect sizes probably vary across studies. Predicted mean rates are close to unity: 0.89 to 0.92 for RES regressions and 0.92 to 0.94 for FES regressions. Confidence intervals include unity or are close to that value. Table 7 displays regression results by beverage. Publication status results for beer are consistent with positive bias, but a positive sign for micro-data is inconsistent with expectations. The predicted RES mean rate for beer in regression (2) is 0.89 and the confidence interval includes unity. The FES regression for beer possibly overcorrects for selection bias. Moderator results for wine-spirits are all insignificant, except the standard error variable. The predicted FES mean rate in regression (4) is 0.91 and the confidence interval includes unity. The Q-statistics in Table 7 reject the FES model and favor the RES model for beer and wine-spirits.

Table 4. Funnel asymmetry regression tests for publication bias $(n=76)$

\begin{tabular}{|c|c|c|}
\hline Test & Value (se) & $95 \% \mathrm{CI}$ \\
\hline Funnel asymmetry test (FAT-PET) & $1.241(0.307)$ & $0.639-1.843$ \\
\hline FES precision is $1 / \mathrm{se}$ & $0.948(0.045)$ & $0.860-1.036$ \\
\hline R-sq. & 0.886 & \\
\hline F-stat. (p-value) & $575.8(0.000)$ & \\
\hline \multicolumn{3}{|l|}{ Precision effect test (PEESE) } \\
\hline Std. error variable & $1.871(0.419)$ & $1.050-2.692$ \\
\hline FES precision is $1 / \mathrm{se}$ & $1.022(0.035)$ & $0.953-1.091$ \\
\hline R-sq. & 0.951 & \\
\hline F-stat. (p-value) & $508.5(0.000)$ & \\
\hline \multicolumn{3}{|l|}{ Lin-Chu test } \\
\hline Intercept & $2.087(0.333)$ & $1.434-2.740$ \\
\hline RES precision is $1 /(\mathrm{se}+\mathrm{T})$ & $0.513(0.108)$ & $0.301-0.725$ \\
\hline R-sq. & 0.164 & \\
\hline F-stat. (p-value) & $14.47(0.000)$ & \\
\hline
\end{tabular}

Notes: Dependent variable is standardized effect size. Heteroskedastic-consistent standard errors in parentheses. 
Table 5. Cumulative meta-analysis results

\begin{tabular}{|c|c|c|c|}
\hline Beverage $\&$ model & Cumulative mean (se) & Cumulative wt. \% & $95 \% \mathrm{CI}$ \\
\hline \multicolumn{4}{|l|}{ All - FES model } \\
\hline First 15 estimates & $1.023(0.014)$ & 78.7 & $0.996-1.051$ \\
\hline First 30 & $1.023(0.013)$ & 94.5 & $0.998-1.047$ \\
\hline Median - First 38 & $1.028(0.013)$ & 96.8 & $1.004-1.053$ \\
\hline First 45 & $1.031(0.012)$ & 98.0 & $1.007-1.056$ \\
\hline All 76 & $1.044(0.012)$ & 100.0 & $1.020-1.068$ \\
\hline \multicolumn{4}{|l|}{ All - RES model } \\
\hline First 15 estimates & $1.004(0.040)$ & 37.2 & $0.925-1.083$ \\
\hline First 30 & $1.023(0.042)$ & 67.3 & $0.942-1.105$ \\
\hline Median - First 38 & $1.055(0.039)$ & 78.0 & $0.978-1.132$ \\
\hline First 45 & $1.071(0.038)$ & 85.2 & $0.997-1.146$ \\
\hline All 76 & $1.164(0.038)$ & 100.0 & $1.089-1.239$ \\
\hline \multicolumn{4}{|l|}{ Beer - FES model } \\
\hline First 10 estimates & $0.959(0.036)$ & 75.6 & $0.888-1.030$ \\
\hline Median - First 20 & $1.085(0.033)$ & 91.4 & $1.020-1.149$ \\
\hline First 30 & $1.123(0.032)$ & 98.4 & $1.061-1.186$ \\
\hline All 40 & $1.137(0.031)$ & 100.0 & $1.076-1.199$ \\
\hline \multicolumn{4}{|l|}{ Beer - RES model } \\
\hline First 10 estimates & $0.935(0.074)$ & 36.5 & $0.790-1.081$ \\
\hline Median - First 20 & $1.216(0.107)$ & 66.8 & $1.006-1.425$ \\
\hline First 30 & $1.320(0.096)$ & 90.2 & $1.131-1.509$ \\
\hline All 40 & $1.395(0.094)$ & 100.0 & $1.211-1.579$ \\
\hline \multicolumn{4}{|l|}{ Wine-spirit - FES model } \\
\hline First 10 estimates & $1.038(0.015)$ & 76.4 & $1.008-1.068$ \\
\hline Median -- First 18 & $1.021(0.014)$ & 96.9 & $0.995-1.048$ \\
\hline First 30 & $1.024(0.013)$ & 99.7 & $0.998-1.050$ \\
\hline All 36 & $1.027(0.013)$ & 100.0 & $1.001-1.053$ \\
\hline \multicolumn{4}{|l|}{ Wine-spirit - RES model } \\
\hline First 10 estimates & $1.027(0.051)$ & 49.1 & $0.927-1.127$ \\
\hline Median -- First 18 & $0.998(0.039)$ & 82.6 & $0.922-1.075$ \\
\hline First 30 & $1.019(0.037)$ & 97.6 & $0.947-1.091$ \\
\hline All 36 & $1.040(0.037)$ & 100.0 & $0.967-1.112$ \\
\hline
\end{tabular}

Notes: Effect size estimates arrayed in ascending order from smallest to largest standard errors and added sequentially to the sample. 
Table 6. Meta-regressions - Alcohol tax pass-through rates

\begin{tabular}{|c|c|c|c|c|c|c|}
\hline Variable & $\begin{array}{c}\text { (1) } \\
\text { Alcohol }\end{array}$ & $\begin{array}{c}(2) \\
\text { Alcohol }\end{array}$ & $\begin{array}{c}\text { (3) } \\
\text { Alcohol }\end{array}$ & $\begin{array}{c}(4) \\
\text { Alcohol }\end{array}$ & $\begin{array}{c}\text { (5) } \\
\text { Alcohol }\end{array}$ & $\begin{array}{c}(6) \\
\text { Alcohol }\end{array}$ \\
\hline Intercept & $\begin{array}{c}0.948 \\
(0.105)^{*}\end{array}$ & $\begin{array}{c}0.859 \\
(0.131)^{*}\end{array}$ & $\begin{array}{c}0.866 \\
(0.162)^{*}\end{array}$ & $\begin{array}{c}0.934 \\
(0.044)^{*}\end{array}$ & $\begin{array}{c}0.922 \\
(0.049)^{*}\end{array}$ & $\begin{array}{c}1.003 \\
(0.052)^{*}\end{array}$ \\
\hline $\begin{array}{l}\text { Std. error } \\
\text { variable }\end{array}$ & $\begin{array}{c}1.484 \\
(0.322)^{*}\end{array}$ & $\begin{array}{c}1.538 \\
(0.348)^{*}\end{array}$ & $\begin{array}{c}1.445 \\
(0.341)^{*}\end{array}$ & $\begin{array}{c}1.271 \\
(0.188)^{*}\end{array}$ & $\begin{array}{c}1.345 \\
(0.193)^{*}\end{array}$ & $\begin{array}{c}1.289 \\
(0.196)^{*}\end{array}$ \\
\hline Wine-spirits $=1$ & $\begin{array}{l}-0.078 \\
(0.101)\end{array}$ & $\begin{array}{l}-0.089 \\
(0.102)\end{array}$ & $\begin{array}{l}-0.038 \\
(0.112)\end{array}$ & $\begin{array}{c}0.013 \\
(0.039)\end{array}$ & $\begin{array}{c}0.003 \\
(0.039)\end{array}$ & $\begin{array}{c}0.013 \\
(0.040)\end{array}$ \\
\hline Not-US =1 & -- & $\begin{array}{c}0.067 \\
(0.108)\end{array}$ & -- & -- & $\begin{array}{c}0.038 \\
(0.029)\end{array}$ & -- \\
\hline Published = 1 & -- & $\begin{array}{c}0.123 \\
(0.098)\end{array}$ & -- & -- & $\begin{array}{l}-0.044 \\
(0.030)\end{array}$ & -- \\
\hline $\mathrm{OLS}=1$ & -- & -- & $\begin{array}{l}-0.062 \\
(0.144)\end{array}$ & -- & -- & $\begin{array}{c}-0.208 \\
(0.040)^{*}\end{array}$ \\
\hline Micro-data $=1$ & -- & -- & $\begin{array}{c}0.100 \\
(0.127)\end{array}$ & -- & -- & $\begin{array}{l}-0.043 \\
(0.033)\end{array}$ \\
\hline Real data $=1$ & -- & -- & $\begin{array}{c}0.068 \\
(0.123) \\
\end{array}$ & -- & -- & $\begin{array}{c}0.019 \\
(0.042) \\
\end{array}$ \\
\hline Q-stat. (p-value) & -- & -- & -- & $\begin{array}{c}366.4 \\
(0.000)\end{array}$ & $\begin{array}{c}363.6 \\
(0.000)\end{array}$ & $\begin{array}{c}331.0 \\
(0.000)\end{array}$ \\
\hline T-sq. & 0.048 & 0.054 & 0.050 & -- & -- & -- \\
\hline R-sq. & 0.274 & 0.300 & 0.302 & 0.133 & 0.140 & 0.233 \\
\hline Smpl. size $n$ & 76 & 76 & 76 & 76 & 76 & 76 \\
\hline Model & random & random & random & fixed & fixed & fixed \\
\hline $\begin{array}{l}95 \% \text { CI for } \\
\text { intercept }\end{array}$ & $0.74-1.16$ & $0.60-1.12$ & $0.54-1.19$ & $0.85-1.02$ & $0.83-1.02$ & $0.90-1.10$ \\
\hline $\begin{array}{l}\text { Pred. mean rate } \\
\text { (se) }\end{array}$ & $\begin{array}{c}0.912 \\
(0.060)^{*}\end{array}$ & $\begin{array}{c}0.893 \\
(0.070)^{*}\end{array}$ & $\begin{array}{c}0.920 \\
(0.065)^{*}\end{array}$ & $\begin{array}{c}0.941 \\
(0.028) *\end{array}$ & $\begin{array}{c}0.922 \\
(0.031)^{*}\end{array}$ & $\begin{array}{c}0.934 \\
(0.032)^{*}\end{array}$ \\
\hline $\begin{array}{l}95 \% \text { CI for pred. } \\
\text { mean }\end{array}$ & $0.80-1.03$ & $0.76-1.03$ & $0.79-1.05$ & $0.89-1.00$ & $0.86-0.98$ & $0.87-1.00$ \\
\hline
\end{tabular}

Notes: Knapp-Hartung standard errors in parentheses for RES coefficients. Asterisks indicate significance at the $95 \%$ confidence level compared to zero. Random-effects models use method-of-moments for the between-study variance. R-sq. values based on weighted least-squares. Predicted mean rates set the value of the standard error variable equal to zero and all other covariates at their sample means. Variance inflation factors (VIF) for standard error variable in random-effects regressions are 1.13, 1.35, and 1.28. For fixed-effects regressions, VIFs are 1.29, 1.36, and 1.39.

Table 7. Meta-regressions by beverage - Alcohol tax pass-through rates

\begin{tabular}{|c|c|c|c|c|c|c|}
\hline Variable & $\begin{array}{c}(1) \\
\text { Beer }\end{array}$ & $\begin{array}{c}(2) \\
\text { Beer }\end{array}$ & $\begin{array}{c}(3) \\
\text { Beer }\end{array}$ & $\begin{array}{c}\text { (4) } \\
\text { Wine-spirit }\end{array}$ & $\begin{array}{c}\text { (5) } \\
\text { Wine-spirit }\end{array}$ & $\begin{array}{c}\text { (6) } \\
\text { Wine-spirit }\end{array}$ \\
\hline Intercept & $\begin{array}{c}0.959 \\
(0.162)^{*}\end{array}$ & $\begin{array}{c}0.400 \\
(0.209)\end{array}$ & $\begin{array}{c}0.449 \\
(0.081)^{*}\end{array}$ & $\begin{array}{c}0.912 \\
(0.055)^{*}\end{array}$ & $\begin{array}{c}0.936 \\
(0.083)^{*}\end{array}$ & $\begin{array}{c}0.981 \\
(0.030)^{*}\end{array}$ \\
\hline $\begin{array}{l}\text { Std. error } \\
\text { variable }\end{array}$ & $\begin{array}{c}1.498 \\
(0.468)^{*}\end{array}$ & $\begin{array}{c}1.694 \\
(0.424)^{*}\end{array}$ & $\begin{array}{c}2.234 \\
(0.273)^{*}\end{array}$ & $\begin{array}{c}1.185 \\
(0.368)^{*}\end{array}$ & $\begin{array}{c}1.253 \\
(0.369)^{*}\end{array}$ & $\begin{array}{c}0.882 \\
(0.282)^{*}\end{array}$ \\
\hline Wine-only $=1$ & -- & -- & -- & $\begin{array}{l}-0.006 \\
(0.121)\end{array}$ & $\begin{array}{c}0.063 \\
(0.132)\end{array}$ & $\begin{array}{c}0.035 \\
(0.065)\end{array}$ \\
\hline Published $=1$ & -- & $\begin{array}{c}0.558 \\
(0.172)^{*}\end{array}$ & $\begin{array}{c}0.398 \\
(0.065)^{*}\end{array}$ & -- & $\begin{array}{l}-0.122 \\
(0.096)\end{array}$ & $\begin{array}{c}-0.110 \\
(0.039) *\end{array}$ \\
\hline Micro-data $=1$ & -- & $\begin{array}{c}0.427 \\
(0.176)^{*}\end{array}$ & $\begin{array}{c}0.203 \\
(0.065)^{*}\end{array}$ & -- & $\begin{array}{r}0.005 \\
(0.084) \\
\end{array}$ & $\begin{array}{c}0.022 \\
(0.029) \\
\end{array}$ \\
\hline Q-stat. (p-value) & -- & -- & $\begin{array}{c}151.9 \\
(0.000)\end{array}$ & -- & -- & $\begin{array}{c}148.8 \\
(0.000)\end{array}$ \\
\hline T-sq. & 0.177 & 0.160 & -- & 0.026 & 0.027 & -- \\
\hline R-sq. & 0.212 & 0.451 & 0.380 & 0.257 & 0.298 & 0.109 \\
\hline Smpl. size $\mathrm{n}$ & 40 & 40 & 40 & 36 & 36 & 36 \\
\hline Model & random & random & fixed & random & random & fixed \\
\hline $\begin{array}{c}95 \% \text { CI for } \\
\text { intercept }\end{array}$ & $0.64-1.28$ & $-0.01-0.81$ & $0.29-0.61$ & $0.80-1.02$ & $0.77-1.10$ & $0.92-1.04$ \\
\hline $\begin{array}{l}\text { Pred. mean rate } \\
\qquad(\mathrm{se})\end{array}$ & $\begin{array}{c}0.959 \\
(0.162)^{*}\end{array}$ & $\begin{array}{c}0.873 \\
(0.145)^{*}\end{array}$ & $\begin{array}{c}0.720 \\
(0.057)^{*}\end{array}$ & $\begin{array}{c}0.911 \\
(0.057)^{*}\end{array}$ & $\begin{array}{c}0.901 \\
(0.059)^{*}\end{array}$ & $\begin{array}{c}0.952 \\
(0.027)^{*}\end{array}$ \\
\hline $\begin{array}{l}95 \% \text { CI for pred. } \\
\text { mean }\end{array}$ & $0.64-1.28$ & $0.59-1.16$ & $0.61-0.83$ & $0.80-1.02$ & $0.79-1.02$ & $0.90-1.00$ \\
\hline
\end{tabular}

Notes: Knapp-Hartung standard errors in parentheses for RES coefficients. Asterisks indicate significance at the $95 \%$ confidence level compared to zero. Random-effects models use method-of-moments for the between-study variance. R-sq. values based on weighted least-squares. Predicted mean rates set the value of the standard error variable equal to zero and all other covariates at their sample means. Variance inflation factors (VIF) for standard error variable in beer regressions are 1.00,1.02, and 1.06. For wine-spirits regressions, VIFs are 1.10, 1.11, and 1.12. 


\section{Discussion}

Overall, the regression results in Tables 6 and 7 are consistent with an approximate pass-through rate of unity regardless of beverage. Confidence intervals, however, consistently allow for under- and overshifting of taxes, so caution is dictated with use of point values only. For these data, meta-regression results provide support for the RES model because tests based on Q-statistics reject the FES model. The possible overshifting of beer taxes is identified as a topic for further research, although predicted means in Table 7 are consistent with full pass-through of beer taxes. These results are obtained using a broader set of methods and tests than previously reported in [6]. It is reassuring that RES methods - greater weight for less precise studies - produce much the same results as FES methods, but apply to a broader set of possible circumstances. Correcting for publication bias, meta-analysis using both models and a variety of tests yields the following: (1) funnel plots and asymmetry tests indicate that publication bias affects the sample of estimates; (2) trim-and-fill estimates for bias-adjusted means are close to unity, regardless of beverage type or model; (3) cumulative meta-analysis yields adjusted-means close to unity, except for beer; (4) meta-regressions yield a RES predicted mean for alcohol of 0.89-0.91; beer, 0.87-0.96; and wine-spirits, 0.90-0.91; and (5) RES predicted mean confidence intervals include unity for alcohol and both beverages. The null hypothesis is not rejected regardless of beverage. Finally, tests based on Q-statistics reject the FES model and R-square statistics are 0.30 or smaller in FES regressions.

Fixed-effect and random-effects models represent different approaches to analyzing and synthesizing data with meta-analysis. Although the models use similar techniques, random-effects is more general and represents a more conservative approach to research synthesis. Both models use weighted-means to estimate a population effect, but the RES model allows the true mean to vary from study to study with the global mean being one of the parameters of interest. Both models allow for heterogeneity between studies, but the RES model assumes some portion is not easily identifiable in the form of moderating covariates. Both models allow for confidence intervals about mean values, but the RES model also allows calculation of prediction intervals that present heterogeneity of possible true effects on the same scale as observed effects. In the present study, an average pass-through rate of unity is not rejected based on a variety of tests, but prediction intervals in Tables 2 and 3 are about $0.7-1.6$ on average. Both under- and overshifting of alcohol taxes is possible given existing data. However, predicted means and confidence intervals from meta-regressions in Tables 6 and 7 are generally consistent with full pass-through of alcohol taxes. In contrast, several widely-cited primary studies conclude there is overshifting of alcohol excise taxes, e.g. [45, 46]. Future research should emphasize confidence intervals as a test of pass-through rates, with the null hypothesis being a rate of unity rather than zero.

\section{Conclusions}

Where there is a desire by analysts or users of a meta-analysis to generalize or make inferences about similar populations, choice of model is important. It is generally held that this should be done initially, rather than as part of a sensitivity analysis $[1,2] .{ }^{15}$ However, Anderson and Kichkha [11] argue that meta-analyses in economics are subject to subjectivity on the part of analysts, including selection of studies, selection of covariates, choice of weights, and interpretation of results. ${ }^{16}$ The present study has emphasized choice of weights but in the context of a wider set of procedures and tests than commonly used in economics. Anderson and Kichkha [11] also characterize meta-regression analysis as akin to model specification searches (i.e., data mining), so they claim results of significance have little importance and are potentially misleading as a guide for primary researchers. However, confidence and prediction intervals reported in this paper provide necessary support to significance levels for point estimates, i.e., the focus is not on conventional statistical significance. Some of these criticisms can be addressed by conducting a narrative review in conjunction with a meta-analysis. As a reaction to these and other criticisms of meta-analysis, the present study provides a summary of methods that go beyond exploratory FES meta-regressions. The study finds that economic data for alcohol tax pass-through rates is highly dispersed and heterogenous, which supports application of the RES model. For economic data and econometric estimates, this does not seem an unusual finding.

\section{Appendix A. Pass-Through Studies in the Meta-Analysis}

- Ally, A.K., Meng, Y., Chakraborty R., Dobson, P.W., Seaton, J., Holmes, J., et al., "Alcohol tax pass-through across the product and price range: Do retailers treat cheap alcohol differently?" Addiction, vol. 109, no. 12, pp. 1994-2002, 2014. https://doi.org/10.1111/add.12590.

15 For example, estimates for value of a statistical life (VSL) is the most widely-studied area in economics using meta-analysis, with at least 15 meta-analyses [47-50]. The objective in both primary studies and meta-analyses might be a value-transfer for use in a benefit-cost calculation, so it is important to consider the robustness of FES models for such inferences. For additional discussion, see [51] and more generally [52-54].

16 In any meta-analysis there are numerous substantive judgements to be made including several illustrated here, such as selection of primary studies, sample of estimates, selection of effect size, and choice of weights. These procedures are a common source of criticism and not unique to Anderson and Kichkha. The "practice of meta-analysis" is discussed more thoroughly in other sources; see, for example, [3, 13, 24, 55-57]. 
- Ardalan, A., Kessing, S.G., "Tax pass-through in the European beer market," Paper No. 47-2017, Philipps University of Marburg, 2017. Accessed 5/16/21: https://www.econstor.eu/bitstream/10419/174343/1/47-201 7_ardalan.pdf

- Baker, P., Brechling, V., "The impact of excise duty changes on retail prices in the UK," Fiscal Studies, vol. 13, no. 2, pp. 48-65, 1992. https://www.jstor.org/stable/24437288.

- Bako, B., Berezvai, Z., "Excise tax overshifting in the Hungarian beer market," Discussion paper, Corvinus University of Budapest, 2013. Accessed 5/16/21: http://unipub.lib.uni-corvinus.hu/1263/1/tax_overflow.pdf.

- Barzel, Y., "An alternative approach to the analysis of taxation," Journal of Political Economy, vol. 84, no. 6, pp. 1177-97, 1976. https://www.journals.uchicago.edu/doi/10.1086/260507.

- Bergman, U.M., Hansen, N.L., "Are excise taxes on beverages fully passed through to prices? The Danish experience," FinanzArchiv, vol. 75, no. 4, pp. 323-56, 2019. doi: 10.1628/fa-2019-0010.

- Carbonnier, C., "Pass-through of per unit and ad valorem consumption taxes: Evidence from alcoholic beverages in France," The B.E. Journal of Economic Analysis and Policy, vol. 13, no. 2, pp. 837-63, 2013. https://doi.org/10.1515/bejeap-2013-0047.

- Chua, J.D., "Essays in Public Economics," Ph.D. dissertation, Harvard University, 2000. Accessed 5/16/21: http://www.worldcat.org/title/essays-in-public-economics/ oclc/77070465.

- Conlon C.T., Rao, N.S., "Discrete prices and the incidence and efficiency of excise taxes," American Economic Journal: Economic Policy, vol. 12, no. 4, pp. 111-43, 2016. doi: 10.1257/pol.20160391.

- Cook, P.J., "The effect of liquor taxes on drinking, cirrhosis, and auto accidents" in M.H. Moore, D.R. Gerstein (eds.), "Alcohol and Public Policy: Beyond the Shadow of Prohibition," National Academy Press, pp. 255-85, 1981.

- Hanson, A., Sullivan, R., "Incidence and salience of alcohol taxes: Do consumers overreact?" Public Finance Review, vol. 44, no. 3, pp. 344-69, 2016. https://doi.org/10.1177\%2F1091142115591204.

- Harding, M., Leibtag, E., Lovenheim, M.F., "The heterogeneous geographic and socioeconomic incidence of cigarette and beer taxes: Evidence from Nielsen Homescan data," Discussion paper, Cornell University, 2010. doi:10.1257/POL.4.4.169.

- Hindriks, J., Serse, V., "Heterogeneity in the tax pass-through to spirits retail prices: Evidence from Belgium," Paper 2018/04, Center for Operations Research and Econometrics, Catholic University of Louvain, 2018. Accessed $5 / 16 / 21$ https://dial.uclouvain.be/pr/boreal/object/boreal:195857.

- Hunt, P., Rabinovich, L., Baumberg, B., "Preliminary assessment of the economic impacts of alcohol pricing policy options in the UK," Rand Europe Report to the Home Office TR-858-HO, Rand Europe, 2010. Accessed 5/16/21: https://www.rand.org.
- Hunt, P., Pacula, R.L., "Are alcohol taxes still an effective policy lever for raising alcohol prices to improve health? Evidence from the Great Recession," Discussion paper, Rand Corp, 2018. Accessed 5/16/21: https://www.rand.org

- Kenkel, D.S., "Are alcohol tax hikes fully passed through to prices? Evidence from Alaska," American Economic Review, vol. 95, no. 2, pp. 273-77, 2005. doi: $10.1257 / 000282805774670284$.

Loretz, S., Zwirn, G., "Taxation of alcoholic beverages: Estimation of tax revenue effects in the Netherlands and Europe," Research report, Institute for Advanced Studies, 2015. Accessed 5/16/21: http://irihs.ihs.ac.at/3604/

- Mathes, M.T., Carpenter, C.S., "New evidence on beer prices and beer taxes," in M.T. Mathes, "Essays on Health Economics: Effect of Economic Forces on Drinking and Smoking-Related Outcomes," Ph.D. dissertation, Vanderbilt University, pp. 64-82, 2015. Accessed 5/16/21: https://search.proquest.com/docview/1724663795

Niskanen, W.A., "The demand for alcoholic beverages: An experiment in econometric method," Rand Report P-2583, Rand Corp, 1962. Accessed 5/16/21: https://www.rand.org/content/dam/rand/pubs/papers/2008/ P2583.pdf.

Parsons, C., "Towards an empirical industrial organization analysis of the Japanese beer industry," Paper CITS WP 2007-01, Yokohama National University, 2007. Accessed $5 / 16 / 21$ :

https://www.econ.ynu.ac.jp/cessa/publication/pdf/CITSWP 2007-01.pdf.

Pipoblabanan, C., "Essays on Parametric and Nonparametric Estimation of Market Structure and Tax Incidence in the U.S. Brewing Industry," Ph.D. dissertation, Oregon State University, 2008. Accessed 5/16/21: https://ir.library.oregonstate.edu/concern/graduate_thesis_ or_dissertations/x059cb29m.

Rabinovich, L., Hunt, P., Staetsky, L., Goshev, S., Nolte, E., Pedersen, J.S., et al., "Further study on the affordability of alcoholic beverages in the EU: A focus on excise duty pass-through, on- and off-trade sales, price promotions and statutory regulations," Report for the European Commission, Rand Europe, 2012. Accessed 5/16/21: https://www.rand.org/pubs/technical_reports/TR1203.html

Russell, C., Van Walbeek, C., "How does a change in the excise tax on beer impact beer retail prices in South Africa?" South African Journal of Economics, vol. 84, no. 4, pp. 555-73, 2016. https://doi.org/10.1111/saje.12123.

Shang, C., Ngo, A., Chaloupka, F.J., "The pass-through of alcohol taxes to prices in OECD countries," European Journal of Health Economics, vol. 21, no. 1, pp. 855-67, 2020. doi: 10.1007/s10198-020-01177-w.

Shrestha, V., Markowitz, S., "The pass-through of beer taxes to prices: Evidence from state and federal tax changes,' Economic Inquiry, vol. 54, no. 4, pp. 1946-62, 2016. https://doi.org/10.1111/ecin.12343.

Siegel, M., Grundman, J., DeJong, W., Naimi, T.S., King III, C., Albers, A.A., et al., "State-specific liquor excise taxes and retail prices in eight U.S. states, 2012," Substance Abuse, vol. 34, no. 4, pp. 415-21, 2013. http://dx.doi.org/10.1080/08897077.2013.792314. 
- Stehr, M., "The effect of Sunday sales bans and excise taxes on drinking and cross-border shopping for alcoholic beverages," National Tax Journal, vol. 60, no. 1, pp. 85-105, 2007. http://dx.doi.org/10.17310/ntj.2007.1.05.

- Tasarika, E., “Aspects of International Taxation,” Ph.D. thesis, University of Exeter, 2001. Accessed 5/16/21: https://www.researchgate.net/profile/Euamporn_Phijaisanit /research.

- Tiwary, R., "Determinants of Tax Pass-Through Rates: A Study of the U.S. Beer Industry," Master's thesis, University of Massachusetts Amherst, 2011. Accessed 5/16/21: https://scholarworks.umass.edu/resec_theses/.

- Young, D.J., Bielinska-Kwapisz, A., "Alcohol taxes and beverage prices," National Tax Journal, vol. 55, no. 1, pp. 57-73, 2002. http://dx.doi.org/10.17310/ntj.2002.1.04.

\section{REFERENCES}

[1] Borenstein, M., "Common Mistakes in Meta-Analysis and How to Avoid Them," Biostat, Inc., 2019.

[2] Hedges, L.V., Vevea, J.L., "Fixed- and random-effects models in meta-analysis," Psychological Methods, vol. 3, no. 4,4 pp. $486-504, \quad 1998$ doi.org/10.1037/1082-989X.3.4.486

[3] Borenstein, M., Hedges, L.V., Higgins, J.P.T., Rothstein, H.R., "Introduction to Meta-Analysis," Wiley, 2009.

[4] Borenstein, M., Hedges, L.V., Higgins, J.P.T., Rothstein, H.R., "A basic introduction to fixed-effect and random-effects models of meta-analysis," Research Synthesis Methods, vol. 1, no. 2, pp. 97-111, 2010. doi: 10.1002/jrsm. 12 .

[5] Hedges, L.V., "A random effects model for effect sizes," Psychological Bulletin, vol. 93, no. 2, pp. 388-95, 1983. https://doi.org/10.1037/0033-2909.93.2.388.

[6] Nelson, J.P., Moran, J.R., "Effects of alcohol taxation on prices: A systematic review and meta-analysis of pass-through rates," The B.E. Journal of Economic Analysis \& Policy, vol. 20, no. 1, art20190134, 2019. https://doi.org/10.1515/bejeap-2019-0134

[7] Barzel, Y., "An alternative approach to the analysis of taxation," Journal of Political Economy, vol. 84, no. 6, pp. 1177-97,

1976 https://www.journals.uchicago.edu/doi/10.1086/260507.

[8] Chua, J.D., "Essays in Public Economics," Ph.D. dissertation, Harvard University, 2000. Accessed 5/16/21: http://www.worldcat.org/title/essays-in-public-economics/ oclc/77070465.

[9] Bergman, U.M., Hansen, N.L., "Are excise taxes on beverages fully passed through to prices? The Danish experience," FinanzArchiv, vol. 75, no. 4, pp. 323-56, 2019. doi: 10.1628/fa-2019-0010.

[10] Shang, C., Ngo, A., Chaloupka, F.J., "The pass-through of alcohol taxes to prices in OECD countries," European Journal of Health Economics, vol. 21, no. 1, pp. 855-67, 2020. doi: 10.1007/s10198-020-01177-w.
[11] Anderson, R.G., Kichkha, A., "Replication, meta-analysis, and research synthesis in economics," American Economic Review: Papers and Proceedings, vol. 107, no. 5, pp. 56-9, 2017. doi: 10.1257/aer.p20171033.

[12] Button, K., "The value and challenges of using meta-analysis in transportation economics," Transport Reviews, vol 39, no. 3, pp. 293-308, 2019. https://doi.org/10.1080/01441647.2018.1464078.

[13] Nelson, J.P., Kennedy, P.E., "The use (and abuse) of meta-analysis in environmental and natural resource economics: An assessment," Environmental \& Resource Economics, vol. 42, no. 3, pp. 345-77, 2009. http://dx.doi.org/10.1007/s10640-008-9253-5.

[14] Higgins, J.P.T., Thompson, S.G., Spiegelhalter, D.J., "A re-evaluation of random-effects meta-analysis," Journal of the Royal Statistical Society A, vol. 172, no. 1, pp. 137-59, 2009. https://dx.doi.org/10.1111\%2Fj.1467-985X.2008.00552.x.

[15] IntHout, J., Ioannidis, J.P.A., Rovers, M.M., Goeman, J.J., "Plea for routinely presenting prediction intervals in meta-analysis," BMJ Open, vol. 6, no. 7, art e010247, 2016. doi: 10.1136/bmjopen-2015-010247.

[16] Griffith, R., O'Connell, M., Smith, K., "Tax design in the alcohol market," Journal of Public Economics, vol. 172, no. 1, pp. 20-35, 2019 . https://doi.org/10.1016/j.jpubeco.2018.12.005.

[17] Cook, P.J., "Paying the Tab: The Costs and Benefits of Alcohol Control," Princeton University Press, 2007.

[18] Stern, N., "The effects of taxation, price control and government contracts in oligopoly and monopolistic competition," Journal of Public Economics, vol. 32, no. 2, pp. 133-58, 1987. http://doi.org/10.1016/0047-2727(87)90009-0.

[19] Weyl, E.G., Fabinger, M., "Pass-through as an economic tool: Principles of incidence under imperfect competition," Journal of Political Economy, vol. 121, no. 3, pp. 528-83, 2013.

https://www.journals.uchicago.edu/doi/10.1086/670401.

[20] De Long, J.B., Lang, K., “Are all economic hypotheses false?" Journal of Political Economy, vol. 100, no. 6, pp. 1257-72, 1992. https://www.journals.uchicago.edu/doi/abs/10.1086/26186 0 .

[21] Romer, D., "In praise of confidence intervals," NBER working paper 26672, National Bureau of Economic Research, 2020. $\quad$ Accessed http://www.nber.org/papers/w26672.

[22] Niskanen, W.A., "The demand for alcoholic beverages: An experiment in econometric method," Rand Report P-2583, Rand Corp, 1962. Accessed 5/16/21: https://www.rand.org/.

[23] Hanson, A., Sullivan, R., "Incidence and salience of alcohol taxes: Do consumers overreact?" Public Finance Review, vol. 44, no. 3, pp. 344-69, 2016. https://doi.org/10.1177\%2F1091142115591204.

[24] Rhodes, W., "Meta-analysis: An introduction using regression models," Evaluation Review, vol. 36, no. 1, pp. 
24-71, https://doi.org/10.1177\%2F0193841X12442673.

[25] Hedges, L.V., Olkin, I., "Statistical Methods for Meta-Analysis," Academic Press, 1985.

[26] Thompson. S.G., Sharp, S.J., "Explaining heterogeneity in meta-analysis: A comparison of methods," Statistics in Medicine, vol. 18, no. 20, pp. 2693-2708, 1999. https://doi.org/10.1002/(SICI)1097-0258(19991030)18:20 \%3C2693::AID-SIM235\%3E3.0.CO;2-V.

[27] Stanley, T.D., Doucouliagos, H., "Neither fixed nor random: Weighted least squares meta-analysis," Statistics in Medicine, vol. 34, no. 13, pp. 2116-27, 2015. https://doi.org/10.1002/sim.6481.

[28] Biostat, Inc., "Comprehensive Meta Analysis Version 3.0," Biostat, Inc., 2015.

[29] Higgins, J.P.T., Thompson, S.G., "Quantifying heterogeneity in a meta-analysis," Statistics in Medicine, vol. 21, no. 11, pp. 1539-58, 2002. https://doi.org/10.1002/sim.1186.

[30] Higgins, J.P.T., Thompson, S.G., Deeks, J.J., Altman, D.G., "Measuring inconsistency in meta-analysis," BMJ (British Medical Journal), vol. 327, no. 7414, pp. 557-60, 2003. https://doi.org/10.1136/bmj.327.7414.557.

[31] Card, D., Krueger, A.B., "Time-series minimum-wage studies: A meta-analysis," American Economic Review, vol. 85, no. 2, pp. 238-43, 1995 https://ideas.repec.org/a/aea/aecrev/v85y 1995i2p238-43.ht $\mathrm{ml}$.

[32] Christensen, G., Miguel, E., "Transparency, reproducibility, and the credibility of economics research," Journal of Economic Literature, vol. 56, no. 3, pp. 920-80, 2018. doi: 10.1257/jel.20171350.

[33] Costa-Font, J., McGuire, A., Stanley, T., "Publication selection in health policy research: The winner's curse hypothesis," Health Policy, vol. 109, no. 1, pp. 78-87, 2013. https://doi.org/10.1016/j.healthpol.2012.10.015.

[34] Ioannidis, J.P.A., Stanley, T.D., Doucouliagos, H., "The power of bias in economics research," The Economic Journal, vol. 127, no. 605, pp. f236-f265, 2017. https://doi.org/10.1111/ecoj.12461.

[35] Stanley, T.D., Jarrell, S.B., Doucouliagos, H., "Could it be better to discard $90 \%$ of the data? A statistical paradox," American Statistician, vol. 64, no. 1, pp. 70-7, 2010. https://doi.org/10.1198/tast.2009.08205.

[36] Vevea, J.L., Coburn, K., Sutton, A., "Publication bias," in H. Cooper, L.V., Hedges, J.C. Valentine (eds.), "The Handbook of Research Synthesis and Meta-Analysis," 3rd edn., Russell Sage, pp. 383-429, 2019.

[37] Stanley, T.D., Doucouliagos, H., "Meta-Regression Analysis in Economics and Business," Routledge, 2012

[38] Stanley, T.D., "Meta-regression methods for detecting and estimating empirical effects in the presence of publication selection," Oxford Bulletin of Economics and Statistics, vol. $70, \quad$ no. $1, \quad$ pp. 103-27, 2008 https://doi.org/10.1111/j.1468-0084.2007.00487.x.

[39] Lin, L., Chu, H., "Quantifying publication bias in meta-analysis," Biometrics, vol. 74, no. 3, pp. 785-94, 2018. https://doi.org/10.1111/biom.12817.

[40] Duval, S., Tweedie, R., "Trim and fill: A simple funnel-plot-based method of testing and adjusting for publication bias in meta-analysis," Biometrics, vol. 56, no. 2, pp. 455-63, 2000 https://doi.org/10.1111/j.0006-341x.2000.00455.x.

[41] Konstantopoulos, S., Hedges, L.V., "Statistically analyzing effect sizes: Fixed- and random-effects models," in H. Cooper, L.V. Hedges, J.C. Valentine (eds.), "The Handbook of Research Synthesis and Meta-Analysis," 3rd edn., Russell Sage, pp. 245-79, 2019.

[42] Thompson, S.G., Higgins, J.P.T., "How should meta-regression analyses be undertaken and interpreted?" Statistics in Medicine, vol. 21, no. 11, pp. 1589-73, 2002. https://doi.org/10.1002/sim.1187.

[43] Bruns, S.B., "Meta-regression models and observational research," Oxford Bulletin of Economics and Statistics, vol. 79, no. 5, pp. 637-53, 2017 https://doi.org/10.1111/obes.12172.

[44] Borenstein, M., Hedges, L.V., Higgins, J.P.T., Rothstein, H., "Regression in meta-analysis," Working paper, Biostat, $2015 . \quad$ Accessed 5/16/2021: https://www.meta-analysis.com/downloads/MRManual.pdf

[45] Kenkel, D.S., "Are alcohol tax hikes fully passed through to prices? Evidence from Alaska," American Economic Review, vol. 95, no. 2, pp. 273-77, 2005. doi: $10.1257 / 000282805774670284$.

[46] Young, D.J., Bielinska-Kwapisz, A., "Alcohol taxes and beverage prices," National Tax Journal, vol. 55, no. 1, pp. 57-73, 2002. http://dx.doi.org/10.17310/ntj.2002.1.04.

[47] Doucouliagos, C., Stanley, T.D., Giles, M., “Are estimates of the value of a statistical life exaggerated?" Journal of Health Economics, vol. 31, no. 1, pp. 197-206, 2012. https://doi.org/10.1016/j.jhealeco.2011.10.001

[48] Keller, E., Newman, J.E., Ortmann, A., Jorm, L.R., Chambers, G.M., "How much is a human life worth? A systematic review," Value in Health, in press, 2021. https://doi.org/10.1016/j.jval.2021.04.003.

[49] Kniesner, T.J., Viscusi, W.K., "The value of a statistical life" in "Oxford Research Encyclopedia of Economics and Finance," Oxford University Press, 2019. doi: 10.1093/acrefore/9780190625979.013.138.

[50] Viscusi, W.K., "Best estimate selection bias in the value of a statistical life," Journal of Benefit-Cost Analysis, vol. 9, no. 2, pp. 205-46, 2018 . http://dx.doi.org/10.1017/bca.2017.21.

[51] Nelson. J.P., "Meta-analysis: Statistical methods," in R.B Johnston, J. Rolfe, R.S. Rosenberger, R. Brouwer (eds.), "Benefit Transfer of Environmental and Resource Values: A Guide for Researchers and Practitioners," Springer, pp. 329-56, 2015.

[52] Bergstrom, J.C., Taylor, L.O., "Using meta-analysis for benefit transfer: Theory and practice," Ecological Economics, vol. 60, no. 2, pp. 351-60, 2006. http://dx.doi.org/10.1016/j.ecolecon.2006.06.015.

[53] Johnston, R.B., J. Rolfe, J., Rosenberger, R.S., Brouwer, R. 
(eds.), "Benefit Transfer of Environmental and Resource Values: A Guide for Researchers and Practitioners," Springer, 2015.

[54] Lindhjem, H., Navrud, S., "How reliable are meta-analyses for international benefit transfers?" Ecological Economics, vol. 66, no. 2-3, pp. 425-43, 2008. https://mpra.ub.uni-muenchen.de/11484/.
[55] Card, N.A., "Applied Meta-Analysis for Social Science Research," Guilford Press, 2012.

[56] Cooper, H., Hedges, L.V., Valentine, J.C. (eds.), "The Handbook of Research Synthesis and Meta-Analysis," 3rd edn., Russell Sage Foundation, 2019.

[57] Ringquist, E.J., "Meta-Analysis for Public Policy Management," Jossey-Bass, 2013. 